Tyrone Thomas Carpenter $\cdot$ Simon Ewen

\title{
Audit of changing surgical management of ectopic pregnancies in a large district general hospital in the United Kingdom
}

Published online: 14 July 2004

(C) Springer-Verlag Berlin / Heidelberg 2004

\begin{abstract}
Over the 5 years form 1997 to 2001 we audited all 384 ectopic pregnancies that were treated surgically. The rate of surgically treated ectopic pregnancies expressed as a proportion of maternities ranged from 1.17 to $1.5 \%$. During this time the proportion of these pregnancies treated laparoscopically rose from $28 \%$ to $66 \%$, with the most rapid increases occurring following the appointment of gynaecologists with a special interest in laparoscopic surgery. The mean time taken to treat ectopic pregnancies surgically was the same regardless of whether the procedure was performed by laparotomy of laparoscopy.
\end{abstract}

Keywords Laparoscopic Ectopic pregnancy

\section{Introduction}

Laparoscopic surgery is the treatment of choice for the management of tubal pregnancy [1]. Despite this studies have shown it is far from the norm in the United Kingdom [2]. Factors cited for this include a lack of training of senior and juniors [2] and a general perception that the procedure is more time consuming than its open equivalent. We undertook an audit of all surgically treated ectopic pregnancies between 1997 and 2001 inclusive, in a large district general hospital in the UK to assess compliance with Royal College of Obstetricians and Gynaecologists (RCOG) guidelines [1] and whether factors cited for poor rates of laparoscopic treatment were apparent.

T. T. Carpenter (

Gynaecology Department,

Royal Surrey County Hospital,

Egerton Road, Guildford, Surrey, GU10 1AL, UK

e-mail: t.carpenter@doctors.org.uk

Tel.: +44-7766-521970

S. Ewen

Gynaecology Department,

Portsmouth Hospitals NHS Trust,

Portsmouth, UK

\section{Method}

All ectopic pregnancies treated surgical between January 1997 and December 2001 were identified from the theatre register. Information was extracted from the register and where necessary from patient records. Information was collected on the procedure performed, the grade of surgeon undertaking the procedure, and the total time the patient spent in the operating theatre including anaesthetic time and preparation time.

\section{Results}

The total number of ectopic pregnancies treated surgically during this period was 384 , ranging from 71 to 89 per year. As a percentage of maternities this represented $1.17-1.5 \%$ per year. The operations performed (both open and laparoscopic) are shown in Fig. 1. Ectopic pregnancy was more common on the right than left (ratio 6:5), and in keeping with RCOG guidelines the majority were treated by salpingectomy. The mean time in the operating theatre is shown in Fig. 2, and this is presented according to grade of surgeon in Fig. 3. The mean theatre time for both was $72 \mathrm{~min}$. The proportion of ectopic pregnancies treated by laparoscopic surgery are shown in Fig. 4.

\section{Discussion}

The relatively high numbers of ectopic pregnancies in this audit are indicative of the fact that the hospital is a large district general hospital. As a proportion of maternities the rate is within the expected range. During the period of the audit it was very uncommon for patients with ectopic pregnancy to be managed medically, both because this was a new technique, and because laparoscopic treatment is the recommended treatment of choice by The RCOG [1]. As such this is very close to the total number of ectopic pregnancies during this period.

In keeping with other studies [3, 4] but contrary to popular belief, laparoscopic treatment of ectopic pregnancy does not take longer than its open equivalent. There 
Fig. 1 Number of types of operations performed, 1997-2001

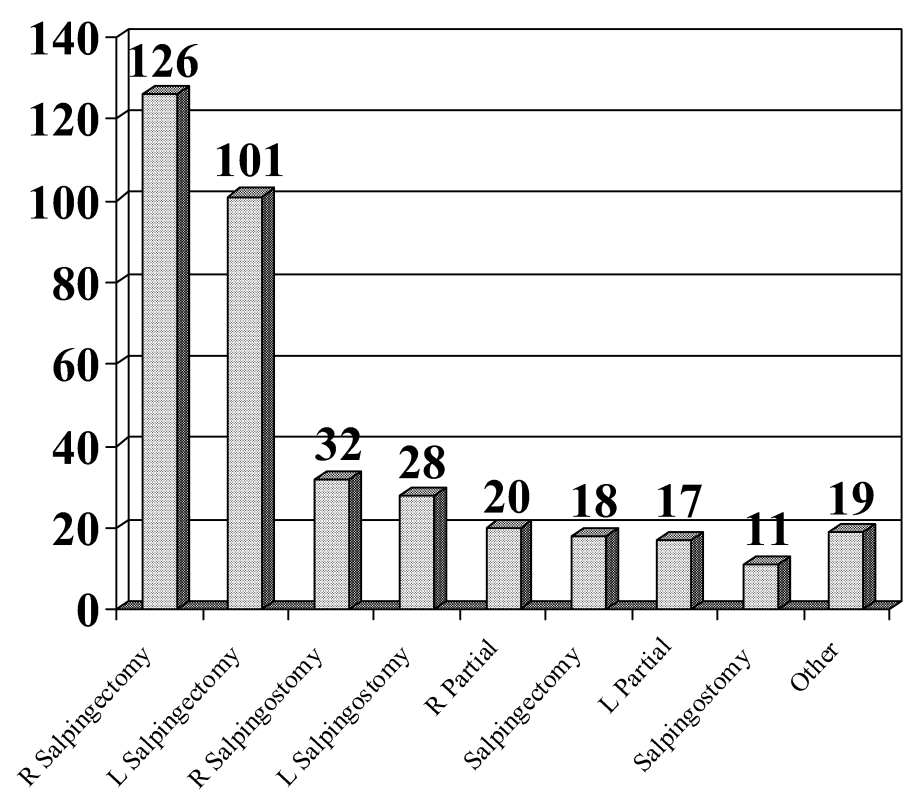

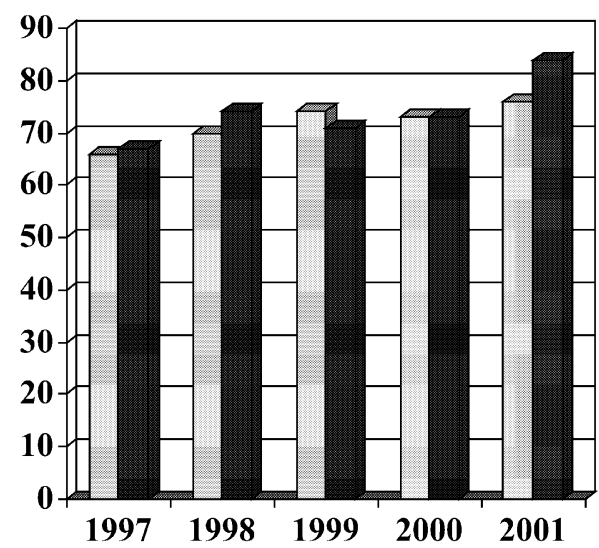

Fig. 2 Comparison of mean duration in the operating theatre (min) between laparoscopic and open procedures in each year

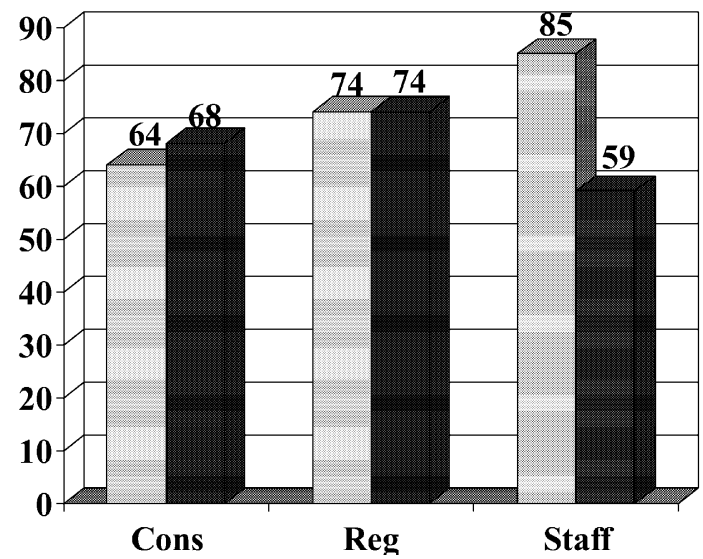

Fig. 3 Comparison of mean duration in the operating theatre (min) by grade of surgeon

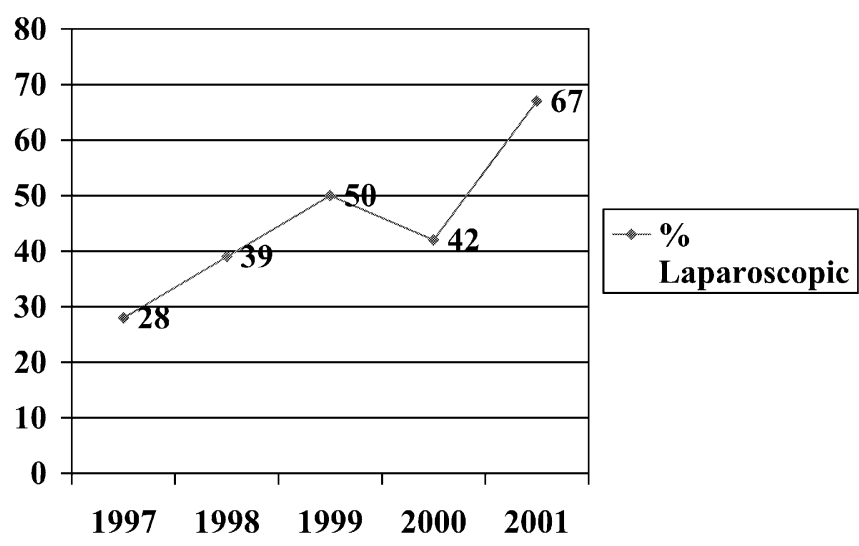

Fig. 4 Proportion of ectopic pregnancies treated by laparoscopic surgery in each year

does appear to be a trend over time for the duration for both techniques to be increasing. However, this is probably a refection of change in anaesthetic practise over the duration of the audit. During the 5 years it was becoming increasingly common for patients to be anaesthetised on the operating table rather than in the anaesthetic room. As the duration in theatre is from entry (whether anaesthetised or not) to exit, the increased anaesthetic time to anaesthetise the patients on the table adds to the duration in theatre.

During the duration of the audit two consultants were appointed with an interest in laparoscopic surgery, one in 1997 and one in 2000. The increase in proportions of ectopic pregnancies treated laparoscopically following these appointments is apparent from Fig. 4 and concurs with the conclusions of Saidi et al. [2] that lack of training of seniors and juniors is a major reason for the excessively high number of ectopic pregnancies that are still treated by laparotomy in the UK. 


\section{Conclusions}

The proportion of ectopic pregnancies treated by laparoscopic surgery can be increased by the appointment of consultants with special interest in this area. The time taken to treat ectopic pregnancies laparoscopically is the same as that taken for laparotomy.

\section{References}

1. Royal College of Obstetricians and Gynaecologists (1999) The management of tubal pregnancies. Guideline no21. RCOG, London

2. Saidi SA, Butler-Manuel SA, Powell MC (1997) Use of laparoscopic surgery for the treatment of ectopic pregnancy in the UK: a national survey. Gynaecol Endosc 8:39-84

3. Shushan A, Mohamed H, Magos AL (1999) How long does laparoscopic surgery really take? Lessons learned from 1000 operative laparoscopies. Hum Reprod 19:39-43

4. Foong C, Connell R, Ganger K, Bridgwood P, Wright J (1995) A comparison of laparoscopic versus conventional surgery in the management of ectopic pregnancy. Gynaecol Endosc 4:2124 